\title{
Magnetic stratigraphy of Chinese loess as a record of natural fires
}

\author{
Günther Kletetschka and Subir K. Banerjee \\ Institute for Rock Magnetism, School of Earth Sciences, University of Minnesota, Minneapolis
}

\begin{abstract}
Magnetic susceptibility records of paleosols and loess show high correlation with oxygen-isotope stratigraphy of ocean sediments [Kukla, 1987], providing a global paleoclimatic record. Different models have been put forth to explain the nature and cause of susceptibility variations, but consensus has not yet been achieved. Our low-temperature studies reveal a secondary magnetite component in paleosols that is characterized by a higher Verwey transition (115K) than that for the magnetite $(100 \mathrm{~K})$ in unaltered loess. The same shift in the Verwey transition can be achieved by heating and cooling loess samples. This is consistent with a new hypothesis that the magnetic signal from paleosols may be produced by natural fires in the past. Natural fire intensity is sensitive to the amount of annual precipitation, so that increased fire-induced susceptibilities should reflect an increase in the humidity of regional climate.
\end{abstract}

\section{Introduction}

The mechanism of magnetic susceptibility (X) enhancement in Chinese paleosol and loess has important implications for the correct interpretation of paleoclimatic changes. Susceptibility enhancement is usually considered to depend on humidity and annual temperature [An at al., 1993; Fassbinder et al., 1990; Kukla et al., 1988; Maher and Taylor, 1988; Taylor et al., 1987; Taylor and Schwertman, 1974; Verosub at al., 1993], whereby a warm and humid climate generates high $X$ values of modern soils. A paleoclimatic indicator independent of $\mathrm{X}$ is wind intensity as measured by relative ${ }^{10} \mathrm{Be}$ concentration [Beer et al., 1993; Heller et al., 1993]. ${ }^{10} \mathrm{Be}$ concentration in loess reflects at a first approximation the decrease in accumulation rate of incoming loess (a dilutant) and is in good correlation with the susceptibility record [Beer et al., 1993]. Insoluble ${ }^{10} \mathrm{Be}$ attached to aerosols stays on the surface $(0-$ $1 \mathrm{~cm}$ ) unless it is mechanically mixed in the soil (e. g., ants, illuviation). However, the sharpness of the ${ }^{10} \mathrm{Be}$ transitions between loess and paleosol indicates that mixing is insignificant.

The pedogenically related $X$ enhancement [e. g., Verosub et al., 1993] should penetrate to a significant depth, for soil develops to $20-200 \mathrm{~cm}$ depth within 1000 years, depending on the difference between precepitation and evaporation [Buol et al., 1989]. Because the effect of fire is restricted to the top 3 $\mathrm{cm}$ of the soil [Woodmansee and Walach, 1978], in principle it can be distinguished from the depth-dependent ambient-temperature formation of magnetic grains by pedogenesis. To il-

\section{Copyright 1995 by the American Geophysical Union.}

Paper number 95GL01324

0094-8534/95/95GL-01324\$03.00 lustrate this, consider that the time necessary for soil to reach an equilibrium depth is less than 1,000 years [Thorpe, 1948; Yaalon, 1983], depending on the difference between precipitation and evaporation [Buol et al., 1989]. In our sample site, Jixian ( $36^{\circ} 10^{\prime}$ lat, $110^{\circ} 40^{\prime}$ long) annual precipitation today is about $550-600 \mathrm{~mm}$, about the same as for the prairie soil in central Missouri [Dahlman and Kucera, 1965], where the soil is $75 \mathrm{~cm}$ thick (50 cm of A horizon and $25 \mathrm{~cm}$ of B horizon). In a cold and dry climate with strong winds accumulation of new loess is too fast to allow soil to significantly develop. After climatic change (see Fig. 1) soil would normally reach an equilibrium depth of $75 \mathrm{~cm}$ within 1000 years if no accumulation occurred. There is good evidence that accumulation of $3 \mathrm{~cm}$ per 1000 years did occur [Beer et al., 1993; Heller et al., 1993], in which case the soil would reach its equilibrium depth not at 75 but at $72 \mathrm{~cm}$ after 1,000 years (see Fig. 1). If we further assume that the warming of climate was abrupt, the pedogenically induced $\mathrm{X}$ should steadily rise from the observed value of unaltered loess $\left(\sim 40 \mathrm{~m}^{3} \mathrm{~kg}^{-1}\right)$ to a maximum for paleosol $(\sim 150$ $\mathrm{m}^{3} \mathrm{~kg}^{-1}$ ) within $72 \mathrm{~cm}$ depth, while the surface was moving up (curve b). Assuming that ${ }^{10} \mathrm{Be}$ does not migrate below the soil surface, the concentration of ${ }^{10} \mathrm{Be}$ should abruptly increase at 0 $\mathrm{cm}$ depth, reflecting the change in accumulation rate after the climate changed (curve a). In the figure, after 30,000 years the climate abruptly switched back to a cold period with higher accumulation rates. The onsets and offsets of both ${ }^{10} \mathrm{Be}$ and pedogenically induced $X$ (curve a and curve $b$ respectively) are significantly different. However, if we take grass fires as a cause of $\mathrm{X}$ increase during the warm period (curve $\mathrm{c}$ ) both onsets of ${ }^{10} \mathrm{Be}$ and $\mathrm{X}$ should correlate. This correlation is well established by measurements of original ${ }^{10} \mathrm{Be}$ isotope data of Chinese loess [Beer et al., 1993; Heller et al., 1993].

Both high fire frequency and temperature of the fire have potential to significantly influence the magnetic susceptibility development. Lightning is a basic cause of fires in grasslands [Komarek, 1971]. A mass of combustible fuel is provided during periods of droughts [Rowe, 1969]. The formation of secondary ferrimagnetic minerals in soils as a result of heating by fire has been well documented [LeBorgne, 1955; Longworth et al., 1989; Maher, 1986; Rummery, 1979]. As the climate becomes more humid both intensity and frequency of fire increase [Woodmanse and Wallach, 1978; Kucera, 1978]; therefore, the humidity increase should result in high $X$ values related to a large amount of newly formed ferrimagnetic minerals.

\section{New magnetic observation}

To distinguish between the secondary $X$ enhancement and primary magnetic component, we measured magnetic properties of Holocene loess and paleosol samples from Jixian ( $36^{\circ}$ $10^{\prime}$ lat, $110^{\circ} 40^{\prime}$ long) in China near Huang He (Yellow River). The magnetic signal causing the susceptibility variation 


\section{GRASS FIRE MODEL OF \\ PALEOSOL DEVELOPMENT UNDER GRASS VEGETATION}

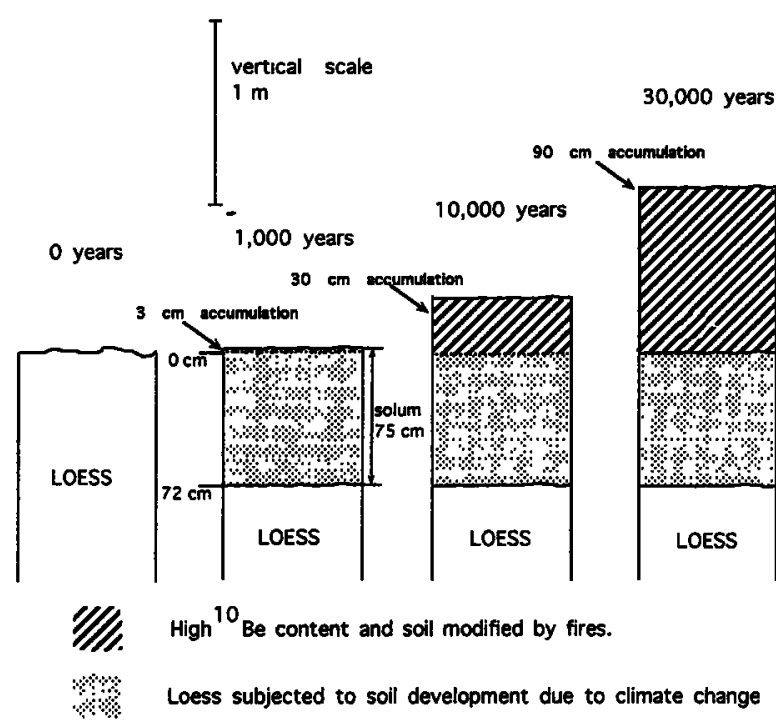

50,000 years

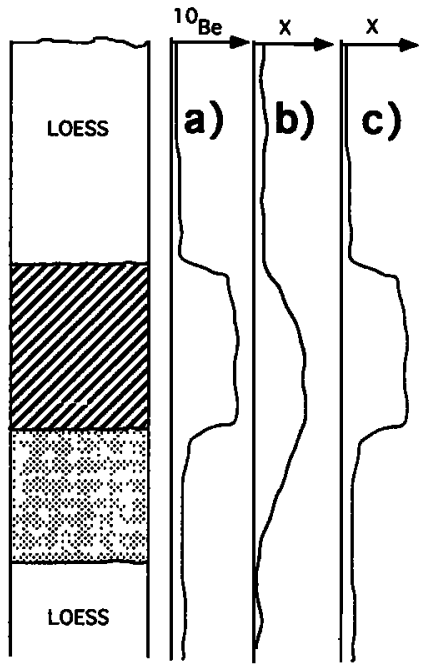

Figure 1. The model of paleosol development (see explanation in text). Curve a) on the right represents the observed ${ }^{10} \mathrm{Be}$ isotope variation reflecting mainly the change in accumulation rate. Curve b) shows a model of susceptibility variations induced by low-temperature pedogenic processes occurring within the depth of solum. Curve c) is another model of susceptibility variation reflecting the transformation by natural fire. Curves a) and c) schematically represent measurement correlation of Heller et al., 1993.

comes from two different types of magnetite. One is carried by loess, and the other is formed after the loess is deposited. These two types of magnetite were recognized by Verwey transition measurements (Fig. 2a) [Verwey et al., 1947; Zuo et al., 1990]. Paleosols and unaltered loess display higher (115K) and

a)

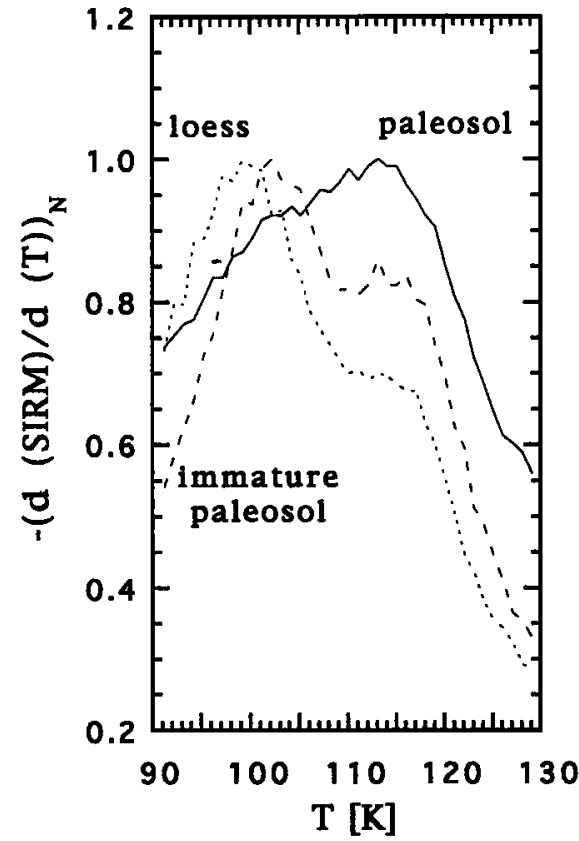

lower $(100 \mathrm{~K})$ Verwey transitions, respectively. Immature paleosol shows both low and high Verwey transitions. The signal coming from magnetite in paleosol samples indicates significant change in magnetite composition. The higher temperature of the Verwey transition usually represents pure stoichiometric

\section{b )}

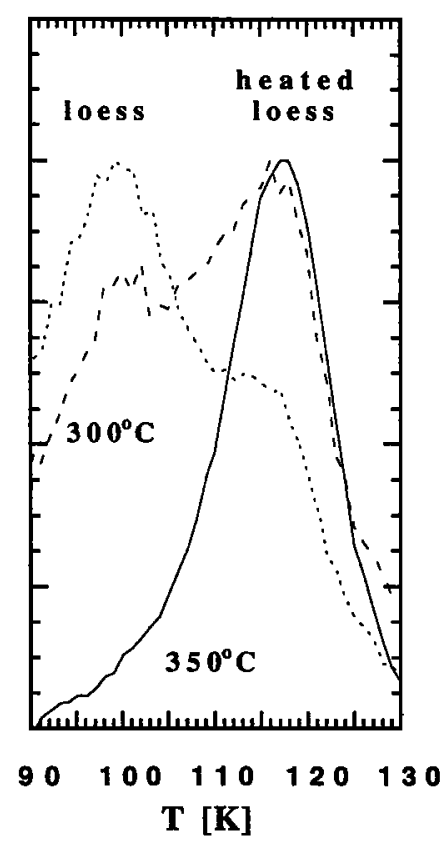

Figure 2. a) The precise positions of the Verwey transitions for both the loess and paleosol are shown by plotting the thermal gradient of the saturation isothermal remanent magnetization (SIRM). The maxima of the curves indicate the lower Verwey transition for loess and one higher for paleosol, respectively. Immature paleosol shows both low and high Verwey transitions. The gradient was taken from the temperature dependence of saturation isothermal remanent magnetization that was acquired at temperature $6 \mathrm{~K}$ in a field of $5 \mathrm{~T}$. b) The figure shows origin of the high Verwey transition as a result of the loess heating. The loess samples were heated in air to different temperatures $\left(300^{\circ} \mathrm{C}, 350^{\circ} \mathrm{C}\right)$ for about 10 minutes. The time required for heating to and cooling from the final temperature was less than 5 minutes each. 
magnetite with a smaller amount of impurities and vacancies [Aragón et al., 1985; Miyahara, 1972]. The parent material for loess originated as a part of igneous and metamorphic processes may have impurities as part of the mineral structure. The purity of magnetite in soils can be the product of either the pedogenic process [e. g., Maher and Taylor, 1988] or thermal conversion of non-magnetic and antiferromagnetic forms of iron by fire [Longworth et al., 1979].

Laboratory heating of loess samples showed that the Verwey transition developed at the same position as in natural paleosols (Fig. 2 b). We believe that the reducing process was initiated by the burning of 1-2\% organic matter present after heating the dry sample up to $350{ }^{\circ} \mathrm{C}$ for about 10 minutes. A lower temperature used in this experiment, $300{ }^{\circ} \mathrm{C}$, showed not only a higher Verwey transition temperature but also a persistent signal from the low Verwey transition temperature that was generated probably by unaltered primary magnetite. At elevated temperature some of the newly formed magnetites can quickly oxidize to maghemite [LeBorgne, 1955]. Because the oxidation process is fast at elevated temperature [Nishitani and Kono, 1989], a portion of the newly formed magnetite can completely oxidize to maghemite, suppressing the magnitude of the Verwey transition. The degree of completeness of oxidation of a portion of newly formed magnetite may explain why the location of the Verwey transition is at high temperature, because it is only the slightly oxidized (less than $1 \%$ of cation deficiency) magnetite that can depress the temperature of the Verwey transition [Aragón et al., 1993].

Temperatures $300^{\circ} \mathrm{C}$ and lower commonly occur during grass fires [Woodmañsee and Wallach, 1978]. As the soil surface slowly migrates upward, all of the accumulating material should be affected by fires. Two to five fires occur in grasslands in a given 10-year period [Hulbert, 1973; Rowe, 1969]. Studies of charcoal in lake sediments show that major forest fires occur every 30 to 80 years [Clark, 1988].

The demonstrated influence of combustion on Verwey transition and our discussion of the observed correlation between

${ }^{10} \mathrm{Be}$ and $\mathrm{X}$ values suggest a fire-induced origin of the fine magnetic fraction in paleosols.

\section{Conclusions}

The possibility of fire-induced $X$ record of Chinese loess has not previously been discussed, and our experimental data suggest a significant production of pure magnetite by combustion after laboratory heating of loess. Because the fire frequency is controlled by annual precipitation [Woodmanse and Wallach, 1978; Kucera, 1978], fire-induced magnetic susceptibility could be an essential part of paleoprecipitation modelling.

We also note that both ${ }^{10} \mathrm{Be}$ records and susceptibility variations in Luochuan indicate that susceptibility enhancement in paleosols occurred near the current soil surface. This is consistent with our fire hypothesis.

Acknowledgments. This research was supported by NSF grant EAR-9206024-03. The Institute for Rock Magnetism is funded by the W. M. Keck Foundation, the National Science Foundation, and the University of Minnesota. IRM contribution 9405 .

\section{References}

An, Z.-S., S. C. Porter, W.-J. Zhou, Y.-C Lu, D. J. Donahue, M. J. Head, X.-H. Wu. J.-Z. Ren and H.-B. Zheng, Episode of strengthened summer monsoon climate of Younger Dryas age on the loess plateau of central China. Quat. Res.. 39, 45-54, 1993.

Aragón, R., P. M. Gehring and S M. Shapiro, Stoichiometry, percolation, and Verwey ordering in magnetite. Phys. Rev. Lett., 70, 1635-1638, 1993.

Beer, J., C.-D. Shen, F. Heller, T.-S. Liu, G. Bonani, B. Dittrich, M. Suter and P. W. Kubik, ${ }^{10} \mathrm{Be}$ and magnetic susceptibility in Chinese loess. Geophys. Res. Lett., 20, 57-60, 1993.

Buol, S. W., F. D. Hole and R. J. McCracken, Soil Genesis and Classification. Iowa State University Press, Ames, 1989.

Clark, J. S., Effect of climate change on fire regimes in northwestern Minnesota. Nature, 334, 233-235, 1988.

Dahlman, R. C. and C. L. Kucera, Root productivity and turnover in native prairie. Ecology, 46. 85-89, 1965.

Fan, Z., The Conservation Atlas of China, pp. 238. Science Press, China, Beijing, 1990

Fassbinder, J. W. E., H. Stanjek and H. Vali, Occurence of magnetic bacteria in soil. Nature, 343, 161-163, 1990.

Heller, F., C.-D. Shen, J. Beer, X.-M. Liu, T.-S. Liu, A. Bronger, M. Suter and G. Bonani, Quantitative estimates of pedogenic ferromagnetic mineral formation in Chinese loess and palaeoclimatic implications. Earth Planet. Sci. Lett., 114, 385-390, 1993.

Hulbert, L C. Management of Konza Prairie to approximate prewhiteman fire influences. In "Third Midwest Prairie Conf." (L. C. Hulbert, Ed.), pp. :14-19. Kansas State Univ., Manhattan, 1993.

Komarek, E. V., Fire Ecology - Grassland and man. In "Tall Timbers Fire Ecology Conference 11.", pp. 169-220, 1971.

Kucera, C L., Grasslands and fire. In "Fire Regimes and Ecosystem Properties.", pp. 90-111. USDA, U. S. Forest Service, GTR-WO-26, 1981, Honolulu, Hawaii, 1978.

Kukla, G. J., Loess stratigraphy in central China. Quat. Sci. Rev., 6, 191$219,1987$.

Kukla, G. J., F. Heller, X.-M. Liu, T.-C. Xu, T.-S. Liu and Z.-S. An, Pleistocene climates dated by magnetic susceptibility. Geology, 16, $811-814,1988$

LeBorgne, E., Susceptibilité magnétique anormale du sol superficiel. Ann. Geophys., Il, 399-419, 1955.

Liu, X.-M., J. Bloemendal, T. Rolph, J. Shaw, T.-S. Liu and F. Heller, Quantitative estimates of palaeoprecipitation in the loess plateau of China. Palaeogeogr. Palaeoclimatol. Palaeoecol., in press, 1994.

Longworth, G., L. W. Becker, R. Thompson, F. Oldfield, J. A. Dearing and T. A. Rummery, Mössbauer and magnetic studies of secondary iron oxides in soils. J. Soll Sci., 30, 93-110, 1979.

Maher, B. A., Characterisation of soils by mineral magnetic measurements. Phys. Earth Planet. Inter., 42, 76-92, 1986.

Maher, B. A. and R. M. Taylor, Formation of ultrafine-grained magnetite in soils. Nature, 336, 368-371, 1988.

Miyahara, Y., Impurity Effects on the Transition Temperature of Magnetite. Journal of the Physical Society of Japan, 32, 629-634, 1972.

Nishitani, T. and M. Kono, Effect of low-temperature oxidation on the remanence properties of titanomagnetites. J. Geomag. Geoelectr., $41,19-38,1989$.

Rowe, J. S., Lightning fires in Saskatchewan grassland. Can. Field-Nat., $83,317-327,1969$.

Rummery, T. A., J Bloemendal, J. A. Dearing, F. Oldfield and R. Thompson, The persistence of fire-induced magnetic oxides in soils and sediments. Ann. Géophys., 35, 103-107, 1979.

Taylor, R. M, B. A. Maher and P. G. Self, Magnetite in soils. I. The synthesis of single-domain and superparamagnetic magnetite. Clay Miner., 22, 4II-422, 1987

Taylor, R. M. and U. Schwertman, Maghemite in soils and its origin. II. Maghemite syntheses at ambient temparature and $\mathrm{pH}$ 7. Clay Miner., 10, 299-310, 1974.

Thorpe, J., How soils develop under grass. In Grass, Yearbook of Agric., pp. 55-66, U. S. Dept. Agric., Washington, D. C., 1948.

Verosub, K. L., P. Fine, M. J. Singer and J. TenPas, Pedogenesis and paleoclimate: Interpretation of the magnetic susceptibility record of Chinese loess-paleosol sequences. Geology, 21, 1011-1014, 1993.

Verwey, E. J., P. W. Haayman and F. C. Romeijn, Physical properties and cation arrangements of oxides with spinel structure. $J$. Chem. Phys., 15, 181-187, 1947.

Woodmansee, R. G., and Wallach, L. S., Effects of fire regimes on biogeochemical cycles. In "Fire Regimes and Ecosystem Properties.", pp. 379-400. USDA, U S. Forest Service, GTR-WO-26, Honolulu, Hawaii, 1978

Yaalon, D. H., Climate, time and soil development. In Pedogenesis and Soil Taxonomy, edited by L. P. Wilding, N. E. Smeck and G. F. Hall, pp. 183-212 New York, 1983.

Zuo, J. M., J. C. H. Spence and W. Petuskey, Charge ordering in magnetite at low temperatures. Phys. Rev., 42B, 8451-8464, 1990.

G. Kletetschka and S. K. Banerjee, Institute for Rock Magnetism, School of Earth Sciences, University of Minnesota, Minnesota, 55455 USA. (e-mail:: klet000l @ gold.tc.umn.edu; chunt@maroon.tc.umn.edu)

(Received December 8, 1994; accepted March 27, 1995.) 